\title{
ANALISIS SISTEM PENGENDALIAN BAHAYA CONVEYOR BELERANG DI PELABUHAN PT. PETROKIMIA GRESIK
}

\section{ANALYSIS OF SULFUR CONVEYOR HAZARD CONTROL SYSTEM AT PORT OF PT PETROKIMIA GRESIK}

\author{
Dewangga Aji Saputra \\ Persatuan Sarjana Kesehatan Masyarakat Indonesia \\ Kota Surabaya \\ E-mail: dewanggaaji.saputra94@gmail.com
}

\begin{abstract}
A technical and administrative control effort should be undertaken to prevent or reduce the impact of workplace accidents. Workplace accidents can be caused by unsafe human behavior and unsafe working environment conditions. This study has a general purpose for analyzing the sulfur conveyor hazard control system in PT Petrokimia Gresik. This research is observational, where as according to the way of data taking and timing of data retrieval is included in cross sectional study. The object of this research is the concession hazard control system of PT Petrokimia Gresik. In this research, I use descriptive analysis technique. The data used in this study is the primary data obtained from observations and interviews and secondary data obtained from corporate documents. The time of this research was conducted on April 20, 2015 until May 20, 2015. The result of the analysis on sulfur conveyor hazard control system in general is good. Lockout and tag out already have the tools and procedures but in its application still less and need to be improved. Emergency stop and emergency pull cord have less than 25\% damage thus can be categorized well. To safeguard the fire hazard is properly installed and has good physical condition. For conveyor safety is in accordance with the standard nf en standards 294 . For safety signs should be added. Administrative control measures are well implemented. Companies are advised to improve safety control efforts as there are still some need to be upgraded to either category.
\end{abstract}

Keywords: analysis, control, conveyor, hazard

\begin{abstract}
ABSTRAK
Perlu dilakukan suatu upaya pengendalian teknis dan administratif untuk mencegah atau mengurangi dampak kecelakaan kerja. Kecelakaan kerja dapat disebabkan oleh perilaku manusia tidak aman dan kondisi lingkungan kerja tidak aman. Penelitian ini memiliki tujuan umum untuk melakukan analisis terhadap sistem pengendalian bahaya conveyor belerang di PT Petrokimia Gresik. Penelitian ini bersifat observasional, sedangkan menurut cara pengambilan data dan segi waktu pengambilan data termasuk dalam penelitian cross sectional. Objek dari penelitian ini ialah sistem pengendalian bahaya conveyor PT Petrokimia Gresik. Pada penelitian ini menggunakan teknik analisa deskriptif. Data yang digunakan dalam penelitian ini ialah data primer yang didapat dari observasi dan wawancara dan data sekunder yang didapat dari dokumen perusahaan. Waktu penelitian ini dilaksanakan pada tanggal 20 April 2015 sampai 20 Mei 2015. Hasil analisis terhadap sistem pengendalian bahaya conveyor belerang secara umum sudah baik. Lockout dan tag out sudah ada sarana dan prosedur nya namun dalam penerapannya masih kurang dan perlu ditingkatkan kembali. Emergency stop dan emergency pull cord memiliki kerusakan kurang dari 25\% dengan demikian dapat dikategorikan baik. Untuk pengaman bahaya kebakaran sudah terpasang dengan baik dan memiliki kondisi fisik yang baik. Untuk pengaman conveyor sudah sesuai dengan standar $n f$ en standards 294. Untuk rambu-rambu keselamatan perlu dilakukan penambahan. Upaya pengendalian administratif sudah dilaksanakan dengan baik. Perusahaan disarankan untuk meningkatkan upaya pengendalian keselamatan karena masih ada beberapa perlu ditingkatkan menjadi kategori baik.
\end{abstract}

Kata kunci: analisis, bahaya, conveyor, pengendalian PENDAHULUAN

Pada era modern ini kemajuan informasi dan teknologi sangatlah pesat untuk mendukung kemajuan industri di Indonesia. Salah satu upaya dalam pengembangan industri di Indonesia

ialah dengan menerapkan ilmu pengetahuan dan teknologi (IPTEK), Penerapan ilmu pengetahuan dan teknologi memang berdampak positif untuk kemajuan perusahaan namun juga memiliki dampak negatif bagi keselamatan dan kesehatan kerja serta lingkungan kerja. 
Unsafe action (tindakan tidak aman) dan unsafe condition (kondisi yang tidak aman) disebabkan karena adanya interaksi manusia dan alat. Penyebab tersebut akan berdampak pada terjadinya kecelakaan atau gangguan keselamatan dan kesehatan pekerja. Kedua hal tersebut dapat menyebabkan kerugian materi maupun korban terhadap perusahaan.

Kecelakaan kerja terjadi karena ada suatu penyebab tidak terjadi begitu saja dan kebetulan. Oleh sebab itu, penyebab tersebut harus diteliti dan dianalisis untuk melakukan suatu tindakan korektif yang ditujukan pada penyebab terjadinya kecelakaan. Dengan suatu upaya pencegahan yang efektif maka penyebab kecelakaan akan dapat dihindari sehingga kecelakaan tidak terjadi.

PT. Petrokimia Gresik adalah perusahaan yang menghasilkan pupuk kimia terbesar se Asia Tenggara dengan varian produk yang cukup banyak hasil dari produksi PT. Petrokimia Gresik. Dengan banyaknya hasil produksi yang dihasilkan maka PT Petrokimia Gresik harus meningkatkan efficiency produksi untuk meningkatkan pendapatan perusahaan dengan penerapan ilmu pengetahuan dan teknologi di perusahaan. Memperkecil biaya produksi dan memperbesar keuntungan merupakan prinsip dasar perusahaan. Oleh karena itu perusahaan menggunakan pesawat angkat angkut untuk mempercepat proses produksi, mempermudah pengangkutan dan memperkecil biaya pengangkutan.

Potensi bahaya yang ada di perusahaan dalam penerapan pesawat angkat angkut harus dikendalikan oleh perusahaan. Upaya pengendalian yang dapat dilakukan oleh perusahaan dapat dilakukan dengan pengendalian teknis, administratif dan alat pelindung diri (APD). Upaya pengendalian bahaya dengan baik maka kemungkinan dan keparahan terjadinya kecelakaan akan sangat berkurang.

Penerapan potensi bahaya dapat dilakukan dengan membentuk suatu tim kerja yang berfokus pada pengendalian dan pembinaan potensi bahaya di tempat kerja. Tim kerja tersebut juga menjadi perwakilan pemerintah dalam penegakan dan pengawasan peraturan keselamatan dan kesehatan kerja di tempat kerja. Peraturan dalam pembentukan tim kerja yang berfokus pada keselamatan kerja diatur pada peraturan perundang-undangan yaitu UU No. 1 tahun 1970 Bab VI pasal 10 tentang panitia penyelenggara kesehatan dan keselamatan kerja.

Keselamatan dan kesehatan kerja merupakan sesuatu yang harus diperhatikan pada era industri modern saat ini. Peningkatan pencegahan risiko kecelakaan dan kesehatan kerja semakin ditingkatkan seiring dengan peningkatan efisiensi dan peningkatan keuntungan bagi perusahaan. Terhambatnya hasil produksi akan berdampak menurunnya keuntungan perusahaan, itu semua dapat disebabkan oleh terjadinya kecelakaan kerja yang ada di perusahaan. Perusahaan wajib memberikan kompensasi pada korban terjadinya kecelakaan yang dapat berakibat meningkatnya pengeluaran yang dikeluarkan oleh perusahaan. Upaya pencegahan kecelakaan dan kesehatan kerja harus dicegah agar tidak terjadi kejadian yang tidak diinginkan. Pengelolaan keselamatan dan kesehatan kerja harus dikelola seperti pengelolaan produksi dan keuangan serta fungsi penting perusahaan lainnya.

PT Petrokimia Gresik memiliki banyak pesawat angkat angkut sebagai alat bantu dalam meningkatkan hasil produksi perusahaan. Jumlah pesawat angkat angkut yang dimiliki berbanding lurus dengan peningkatan risiko dan potensi bahaya yang dimiliki perusahaan. Semakin banyak pesawat angkat angkut maka semakin cepat dan mudah dalam melakukan proses produksi namun juga semakin tinggi risiko dan potensi bahaya yang dimiliki.

Conveyor merupakan salah satu pesawat angkat angkut yang dimiliki oleh PT Petrokimia Gresik. Conveyor digunakan dalam untuk mengangkut bahan produksi dari kapal ke pabrik dan hasil produksi dari pabrik ke kapal. Conveyor dipasang pada area pelabuhan perusahaan. Conveyor sangat mempermudah proses pengangkutan dan berdampak positif bagi perusahaan. Conveyor memiliki potensi bahaya yang cukup besar dan harus dikendalikan potensi bahaya tersebut. Potensi bahaya tersebut dapat mengakibatkan kecelakaan kerja, gangguan kesehatan kerja dan kerugian materi bagi perusahaan. Mengendalikan potensi bahaya conveyor dapat menggunakan sistem pengaman seperti yang diatur pada Peraturan Menteri Tenaga Kerja PER.05/MEN/1985 tentang pesawat angkat angkut khususnya di bab IV tentang pita transport atau conveyor.

Potensi bahaya conveyor dapat dikendalikan dengan penerapan lockout dan tag out, penerapan pengendalian bahaya kebakaran, penerapan pengaman conveyor, penerapan rambu-rambu keselamatan, penerapan upaya pengendalian administratif (pelatihan kerja, prosedur kerja, safety talk, safety meeting).

Hasil wawancara yang dilakukan oleh peneliti saat melaksanakan praktik kerja lapangan di PT. Petrokimia Gresik menjelaskan pada bahwa pernah 
terjadi kejadian nyaris celaka atau near miss pada saat pekerja yang melakukan perbaikan conveyor memperbaiki kerusakan bagian conveyor. Pada saat itu pekerja yang sedang memperbaiki conveyor lupa mengancingkan lengan baju lalu lengan baju tersebut langsung tersangkut pada roller conveyor. Pekerja tersebut selamat pada kejadian tersebut karena emergency pull cord pada conveyor tersebut langsung ditarik oleh pekerja sehingga conveyor dapat langsung berhenti dan kecelakaan tersebut dapat terhindar. Hasil wawancara tersebut menunjukkan bahwa alat pengaman conveyor merupakan suatu hal yang sangat penting dalam upaya pencegahan kecelakaan.

Penelitian Hidayatullah (2013) tentang analisis penerapan sistem lockout/tag out (LOTO) pada bagian operasi dan pemeliharaan di PT. X Tanjung Emas kota Semarang. Penelitian tersebut menunjukkan bahwa hasil penerapan sarana dan prasarana sistem LOTO yang sesuai $=64,29 \%$ tidak sesuai $=35,71 \%$. Penerapan prosedur sistem LOTO yang sesuai $=86,67 \%$ tidak sesuai $=13,33 \%$. Penerapan pembinaan dan pelatihan sistem LOTO yang sesuai $=40 \%$ tidak sesuai $=60 \%$. Penelitian tersebut menunjukkan bahwa terjadi ketidaksesuaian tentang penerapan pembinaan dan pelatihan.

Penelitian Alberto dkk. (2016) yang berjudul A Back Analysis on Conveyor Belt Injury for Better Design for Maintenance Operation. Penelitian tersebut menjelaskan bahwa dari hasil analisa Root Causes Fault Tree Analysis penyebab terjadinya kecelakaan pada conveyor disebabkan oleh kurangnya tindakan pengamanan untuk perawatan operasi (interlock system) berupa emergency stop and emergency pull cord sebagai tindakan pengaman pekerja terhadap bahaya kelalaian manusia dan energi sisa. Bahaya kesalahpahaman dalam mengoperasikan conveyor dengan pekerja perawatan yang dapat menyebabkan kecelakaan, dapat disebabkan oleh rendahnya keterlibatan karyawan dalam pelatihan keselamatan dan kesehatan kerja yang dilakukan oleh perusahaan.

Selain bahaya terjepit yang hampir terjadi pada pekerja conveyor juga memiliki potensi kebakaran. Potensi kebakaran dapat dilihat dari jenis bahan yang diangkut pada conveyor tersebut. Conveyor pada PT. Petrokimia Gresik merupakan pengangkut belerang dari pelabuhan ke pabrik. Belerang merupakan suatu bahan yang mudah terbakar. Titik nyala belerang sangat rendah yaitu $207^{\circ} \mathrm{C}$, dengan titik nyala tersebut belerang merupakan suatu material yang sangat mudah terbakar. Oleh sebab itu pengaman kebakaran pada belerang merupakan suatu hal yang sangat penting, dengan proteksi kebakaran yang baik maka pencegahan kebakaran dapat dilakukan.

Hasil wawancara yang dilakukan peneliti saat melakukan praktik kerja lapangan pada petugas pemadam kebakaran yang memiliki tugas pokok melakukan perawatan pada alat pengaman kebakaran, petugas menjelaskan bahwa masih ada masalah pada kondisi fisik sistem pengaman kebakaran, alat-alat pengaman kebakaran banyak yang mengalami korosif dikarenakan kondisi lingkungan pabrik dan lokasinya yang berdekatan dengan laut. Debu kimia yang dihasilkan pada pengolahan pabrik dapat menyebabkan besi conveyor cepat berkarat dan percikan air laut juga memicu cepatnya terjadi karat pada conveyor. Conveyor tersebut juga belum dilakukan sertifikasi oleh perusahaan. Alat pengendalian kebakaran harus terjaga agar selalu siap digunakan kapanpun, karena kecelakaan tidak ada yang tau kapan akan terjadi.

Penelitian ini memiliki tujuan umum untuk mengevaluasi sistem pengendalian bahaya conveyor belerang di pelabuhan PT. Petrokimia Gresik sebagai upaya pengendalian potensi bahaya. Penelitian ini memiliki tujuan khusus mengidentifikasi penerapan sistem emergency pull cord PT. Petrokimia Gresik, mengidentifikasi penerapan lockout dan tag out, mengidentifikasi penerapan pengendalian bahaya kebakaran PT. Petrokimia Gresik, mengidentifikasi pengaman conveyor PT. Petrokimia Gresik, mengidentifikasi penerapan rambu-rambu keselamatan PT. Petrokimia Gresik, mengidentifikasi upaya pengendalian administratif (pelatihan kerja, prosedur kerja, safety talk, safety meeting) PT. Petrokimia.

\section{METODE}

Metode pada penelitian ini yaitu dengan mengunakan metode observasional dengan rancang bangun penelitian cross sectional. Penelitian dimulai dengan pengumpulan data pada tanggal 20 April 2015 sampai 20 Mei 2015. Teknik yang digunakan dalam pengumpulan data primer yaitu dengan menggunakan teknik wawancara, observasi. Pengumpulan data sekunder dari Human Resources Department. Teknik wawancara dan observasi yang dilakukan untuk mendapatkan data pencegahan bahaya conveyor yang sudah diterapkan sebelumnya di PT. Petrokimia Gresik. Pada penelitian ini variabel yang digunakan ialah (emergency stop, emergency pull cord, lockout, tag out, pengaman 
bahaya kebakaran, desain pengaman conveyor) dan pengendalian administratif (rambu keselamatan dan upaya administrative, pelatihan kerja, prosedur kerja, safety talk, safety meeting). Teknik observasi yang dilakukan yaitu dengan menggunakan lembar checklist yang telah disusun oleh peneliti sedangkan teknik yang digunakan pada saat wawancara yaitu dengan menggunakan panduan wawancara yang telah disusun peneliti. Pengumpulan data sekunder diperlukan untuk mengetahui semua data yang terkait dengan penelitian. Pengolahan dan analisa data, teknik yang digunakan yaitu dengan cara deskriptif dengan menghubungkan dengan teori dan standar peraturan yang terkait.

\section{HASIL}

\section{Emergency Stop dan Emergency Pull Cord}

Conveyor yang digunakan pada penelitian ini yaitu conveyor belerang. Lokasi conveyor tersebut berada pada kiri jalan saat akan menuju dermaga laut pelabuhan. Conveyor yang dimiliki oleh perusahaan terbagi menjadi beberapa bagian yaitu M7001, M7002, M7003, M7004B, M7004A, 29M7005 (1-5) dan M7106-3. Pemasangan emergency stop hanya terpasang pada conveyor belerang yang baru dioperasikan yaitu pada conveyor belerang 29M7005 (1-5), sedangkan pada conveyor belerang yang lama emergency stop belum terpasang namun digantikan dengan menggunakan regular stop yang memiliki fungsi sama yaitu untuk mematikan conveyor. Pada conveyor lama memang tidak ada emergency stop sejak awal conveyor dibangun.

Kerusakan kondisi fisik pada emergency stop dan emergency pull cord disebabkan oleh kondisi lingkungan perusahaan yang korosif karena berdekatan dengan laut dan bahan kimia korosif yang dihasilkan. Kerusakan kondisi fisik terebut menyebabkan tali sling terputus, kerusakan komponen emergency pull cord, selain kerusakan kondisi fisik masalah juga terdapat pada peletakan

Tabel 1. Hasil Observasi Emergency Stop dan Emergency Pull Cord

\begin{tabular}{lcccccc}
\hline \multirow{2}{*}{ Variabel } & \multicolumn{2}{c}{ B } & \multicolumn{2}{c}{ BR } & \multicolumn{2}{c}{ Total } \\
\cline { 2 - 7 } & $\mathbf{n}$ & $\mathbf{\%}$ & $\mathbf{n}$ & $\mathbf{\%}$ & $\mathbf{N}$ & $\mathbf{\%}$ \\
\hline $\begin{array}{l}\text { Emergency } \\
\text { Stop }\end{array}$ & 4 & 80 & 1 & 20 & $\mathbf{5}$ & $\mathbf{1 0 0}$ \\
$\begin{array}{l}\text { Emergency } \\
\text { Pull Cord }\end{array}$ & 65 & 84 & 12 & 16 & $\mathbf{7 7}$ & $\mathbf{1 0 0}$ \\
\hline
\end{tabular}

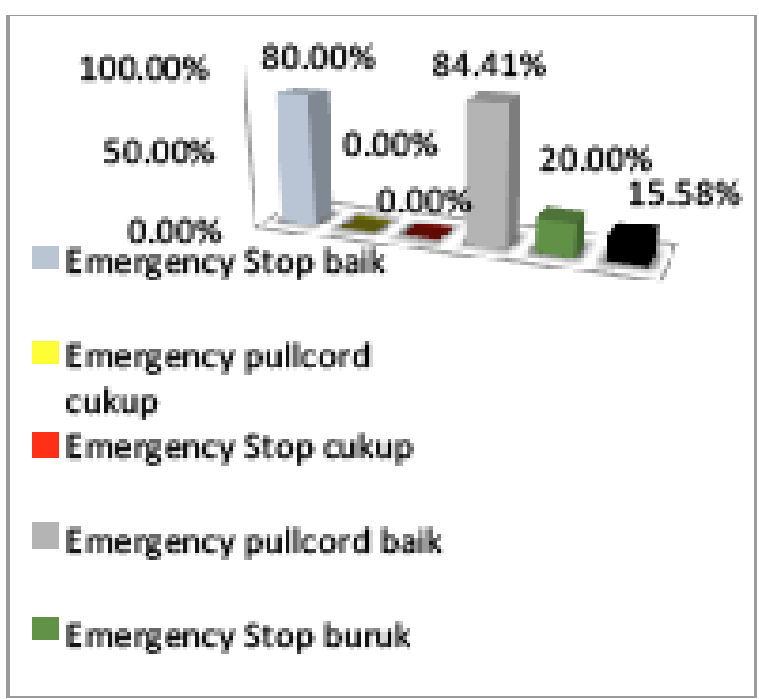

Gambar 1. Grafik Kesesuaian Emergency Stop dan Emergency Pull Cord

emergency stop yang tidak memiliki rambu atau tanda keberadaan dan sulit untuk dijangkau.

Hasil observasi di pelabuhan, emergency stop hanya ada pada conveyor baru saja conveyor 29M7005(1-5) dan 1 dari alat tersebut ada yang memiliki kondisi buruk dikarenakan kondisinya yang buruk yang disebabkan karena alat tersebut tidak dapat dijangkau, tidak terlihat karena tertutup debu dan tidak ada rambu yang menunjukkan keberadaan alat. Emergency pull cord sudah terpasang pada seluruh bagian conveyor namun ada 12 yang kondisinya buruk karena memiliki kerusakan pada kabel sling yang rusak karena lingkungan yang korosif. Kerusakan emergency pull cord pada conveyor M7001 sebanyak 4, M7002 sebanyak 2, M7003 sebanyak 4 dan 29M7005-5 sebanyak 2, kerusakan total pada emergency pull cord sebesar $15,58 \%$ dari jumlah total keseluruhan emergency pull cord pada conveyor belerang. Hasil persentase kerusakan dilihat pada Gambar 1.

\section{Lockout dan Tag out}

Program lockout dan tag out sudah dirancang oleh PT Petrokimia Gresik, namun dalam penerapannya belum semua unit kerja PT Petrokimia Gresik menerapkan program lockout dan tag out. Wawancara yang dilakukan peneliti pada pekerja pelabuhan sebanyak 3 orang, tersebut sebagai penanggung jawab pesawat angkat angkut conveyor. Hasil wawancara tersebut sosialisasi rancangan program lockout dan tag out sebenarnya sudah dilakukan oleh departemen keselamatan 
dan kesehatan kerja. Prosedur dan sarana alat mengenai lockout dan tag out sudah ada saat observasi dilaksanakan namun terkadang program lockout dan tag out tidak diterapkan dan dijalankan menggunakan sarana semestinya.

Penerapan lockout dan tag out pada unit kerja conveyor belerang yaitu dengan menggunakan dua alat berwarna merah dan biru, digunakan untuk operator conveyor sedangkan warna merah digunakan untuk pekerja yang melakukan perbaikan pada conveyor. Penerapan lockout dan tag out terkadang kurang konsisten meskipun prosedur dan sarana lockout dan tag out sudah ada di PT Petrokimia Gresik. Berdasarkan hasil pengamatan yang dilakukan peneliti di lapangan dapat dikatakan penerapan lockout dan tag out dapat dikategorikan cukup.

\section{Pengaman Bahaya Kebakaran}

Sarana pengaman bahaya kebakaran sudah terpasang baik di conveyor belerang PT Petrokimia Gresik. Jalur conveyor belerang di PT Petrokimia Gresik terbagi menjadi dua jalur yaitu jalur conveyor lama dan jalur conveyor baru. Sistem pengamanan kebakaran sudah berjalan baik semua pada conveyor baru. Proteksi keamanan kebakaran juga dapat berjalan secara otomatis pada conveyor baru. Pada conveyor belerang jalur lama conveyor tidak memiliki sistem pemadaman kebakaran secara otomatis sejak dari awal desain conveyor dibuat. Conveyor dipasang sistem pemadaman kebakaran secara otomatis mengingat conveyor sangat panjang dan ada beberapa titik yang susah untuk dijangkau untuk melakukan pemadaman kebakaran.

Sistem pendeteksi panas sudah terpasang di sepanjang conveyor belerang PT. Petrokimia Gresik dari wilayah pelabuhan hingga gudang penyimpanan belerang. Conveyor belerang memiliki sistem pemadaman air yang terhubung pada instalasi hidran dan komponen hidran yaitu water spray, sistem pompa dan sumber air. Alarm kebakaran, pressure switch dan alarm kebakaran merupakan komponen pengaman kebakaran yang sudah terpasang pada sepanjang conveyor belerang.

Hasil observasi yang dilakukan pada sistem pengaman kebakaran yang ada pada conveyor belerang. Kondisi pengaman kebakaran conveyor belerang di pelabuhan PT Petrokimia Gresik dapat dikategorikan baik karena semua alat pengaman kebakaran dapat digunakan untuk pemadaman kebakaran dan memiliki sumber air yang cukup untuk digunakan selama 30 menit. Beberapa titik pengaman kebakaran yang harus dijalankan secara manual namun alat tersebut masih bisa digunakan dan ada petugas yang selalu menjaga berkeliling conveyor saat conveyor digunakan.

\section{Pengaman Conveyor Belerang}

Perlindungan pekerja dari bahaya mekanik conveyor sangatlah penting untuk menjaga keselamatan pekerja, perlu dilakukan pemasangan pengaman conveyor. Hasil observasi saat melakukan pengumpulan data, keadaan conveyor belerang yang ada pada PT. Petrokimia Gresik memiliki ketinggian yang tidak sejajar dengan tempat aktivitas pekerja pada umumnya dan conveyor tersebut tertutup rapat terlindungi di semua sisinya serta tidak mudah dijangkau oleh pekerja, harus menaiki tangga setinggi 10 meter. Pada conveyor belerang memiliki ketinggian yang sejajar dengan aktivitas pekerja oleh karena itu harus diberi pembatas dengan ketinggian khusus. Berdasarkan hasil pengukuran ketinggian pembatas pagar tersebut memiliki ketinggian $170 \mathrm{~cm}$ dan tersebut memiliki jarak $200 \mathrm{~cm}$ dengan conveyor sehingga tidak mudah dijangkau.

Pengaman conveyor dari hulu ke hilir dapat dikategorikan baik. Untuk conveyor terbuka yang ada pada wilayah pelabuhan sudah memiliki ketinggian sesuai dengan perhitungan $n f$ en standards 294 . Sedangkan pada bagian conveyor yang menuju ke gudang sudah berada pada ketinggian 10 meter dari permukaan tanah dan memiliki lalu lintas orang selebar 0,5 meter.

\section{Rambu-Rambu Keselamatan}

Berdasarkan hasil observasi saat melakukan pengumpulan data, pada area conveyor belerang sudah terpasang rambu-rambu sebagai media promosi keselamatan di tempat kerja. Rambu-rambu tersebut antara lain rambu-rambu dilarang merokok, dilarang memancing, dan dilarang memotret, namun masih perlu adanya penambahan rambu-rambu tentang potensi bahaya conveyor itu sendiri. Berdasarkan hasil wawancara dengan departemen keselamatan dan kesehatan kerja (K3), rambu-rambu tersebut sudah dibuatkan dan masih berada di gudang namun memang belum terpasang karena banyaknya rambu-rambu yang akan dipasang. Hasil pengamatan yang dilakukan di gudang memang benar keberadaan rambu-rambu keselamatan conveyor belerang sudah ada di gudang rambu. Pemasangan rambu-rambu keselamatan dapat diletakkan pada beberapa titik 
yang sering digunakan saat pekerja melakukan kegiatan di sepanjang conveyor belerang.

Berdasarkan hasil observasi yang telah dilakukan, rambu-rambu keselamatan yang ada di area conveyor belerang dapat dikategorikan cukup. Arti dari kategori cukup menujukan bahwa rambu-rambu keselamatan yang terpasang dan dalam keadaan baik memiliki jumlah $50-75 \%$ dari seluruh titik yang seharusnya ada rambu-rambu keselamatan. Hal tersebut harus ditingkatkan oleh perusahaan mengingat potensi bahaya conveyor yang cukup besar.

\section{Upaya Pengendalian Administratif}

Pengendalian administratif seperti safety talk, safety meeting, pelatihan kerja, prosedur kerja sudah diterapkan pada pekerja unit conveyor. Berdasarkan hasil observasi saat pengumpulan data upaya pengendalian administratif dikategorikan baik karena telah diterapkan dan diikuti oleh pekerja sebanyak 75-100\%.

PT Petrokimia Gresik membagi pelatihan kerja menjadi dua yaitu pelatihan kerja tetap dan pelatihan kerja kondisional. Pelaksanaan pelatihan kerja saat awal pekerja di perusahaan disebut sebagai pelatihan kerja tetap yang pasti dilakukan oleh perusahaan. Pelatihan yang dilakukan untuk melakukan penyegaran kembali pengetahuan dan kemampuan pekerja disebut pelatihan kerja kondisional. Pelatihan kerja kondisional dapat juga dilakukan saat pekerja memiliki alat baru yang sebelumnya tidak ada. Pelatihan tentang potensi bahaya conveyor belerang saat melakukan loading dan unloading belerang diberikan oleh perusahaan saat pertama kali pekerja bekerja. Program pelatihan tersebut diberikan pada pekerja minimal 1 tahun. Pelatihan kerja yang diberikan oleh perusahaan dapat dikategorikan baik karena diikuti oleh seluruh pekerja. Prosedur kerja mengenai conveyor belerang sudah ada dan diterapkan oleh seluruh pekerja di unit tersebut.

Pengendalian administratif lainnya yaitu dengan menerapkan safety meeting, safety meeting merupakan suatu kegiatan rapat yang dilakukan oleh panitia pembina keselamatan dan kesehatan kerja (P2K3) PT. Petrokimia Gresik yang dilakukan selama 1 bulan sekali. Ada 2 macam safety meeting yaitu safety meeting corporate yang dihadiri oleh direktur produksi, manager, staf keselamatan kerja, dokter perusahaan, direktur anak perusahaan untuk membahas tentang permasalahan, pengendalian dan tindakan pengendalian keselamatan dan kesehatan kerja (K3) dengan tingkat permasalahan besar yang tidak dapat ditangani di unit kerja setempat dan safety meeting unit setempat yang dihadiri oleh general manager, pimpinan unit kerja, staf $\mathrm{K} 3$, kepala bagian, safety representative untuk membicarakan permasalahan, pengendalian dan tindakan pengendalian keselamatan dan kesehatan kerja (K3) dengan tingkat permasalahan kecil

\section{PEMBAHASAN}

Semua conveyor harus dilengkapi dengan emergency pull cord agar para pekerja dapat mengakses untuk pemberhentian conveyor dalam keadaan darurat sesuai dengan peraturan section 373.5 of the Regulation Respecting Occupational Health and Safety in Mines. Emergency pull cord berbentuk tali sling yang terbentang di sepanjang conveyor yang terhubung dengan tombol darurat (Vezina, 2003).

Emergency pull cord sebagai alat pengaman bahaya conveyor sudah dimiliki conveyor belerang PT Petrokimia Gresik namun masih ada beberapa bagian yang mengalami kerusakan. Kerusakan terjadi pada kabel sling yang putus dan keadaan fisiknya yang rusak karena korosif. Kerusakan emergency pull cord dan emergency stop merupakan hal yang sangat disayangkan karena alat tersebut merupakan pelindung yang sangat penting bagi pekerja saat mengalami keadaan darurat seperti terjepit, terhimpit dan sebagainya. Conveyor juga merupakan aset yang sangat penting bagi perusahaan, emergency pull cord dan emergency stop dapat memberikan perlindungan pada conveyor saat keadaan darurat seperti mencegah nya api semakin meluas.

Berdasarkan hasil observasi yang dilakukan di lapangan pada unit kerja conveyor belerang sudah melakukan beberapa aspek penting dalam melakukan penerapan lockout dan tag out (LOTO) yaitu melaksanakan program LOTO untuk pengendalian energi, menggunakan perangkat lockout untuk mengunci saat dilakukan perbaikan, menggunakan tag out sebagai pelengkap lockout, memastikan lockout digunakan secara sempurna, melakukan pendokumentasian pada LOTO, memastikan menggunakan LOTO yang sesuai standar, memastikan bahwa LOTO dapat mengidentifikasi siapa yang menggunakan LOTO tersebut, menetapkan kebijakan dan prosedur LOTO, dan memberikan pelatihan yang efektif.

Beberapa aspek penting tersebut sudah ada di PT Petrokimia Gresik namun dalam penerapannya 
masih perlu ditingkatkan kembali karena masih ada beberapa yang kurang sesuai dengan prosedur dalam penerapannya. Alat dan sarana LOTO sudah tersedia dan perusahaan sudah melakukan sosialisasi tentang penggunaan LOTO. Hal yang menyebabkan tidak diterapkannya LOTO dikarenakan kesadaran dari pekerja sendiri yang kurang dalam melakukan pelaksanaan LOTO.

Pengalaman kerja yang menyebabkan tidak ada kecelakaan yang disebabkan oleh kegagalan energi. Pemikiran seperti itu seharusnya dihindari, kecelakaan dapat terjadi kapan saja dan dimana saja, kelalaian dalam melakukan penerapan prosedur dapat berdampak kerugian sangat besar pada perusahaan. Penerapan LOTO merupakan suatu upaya meningkatkan keselamatan dan kesehatan kerja. Pengendalian bahaya dengan menggunakan LOTO harus dilakukan secara tepat agar jika terjadi kesalahpahaman saat melakukan pekerjaan, LOTO dapat melindungi tenaga kerja agar tidak terjadi kecelakaan kerja.

Budaya keselamatan dan kesehatan kerja harus ditingkatkan di lingkungan kerja untuk menangani permasalahan ketidakpatuhan terhadap prosedur LOTO. Penegakan prosedur dan pengawasan terhadap prosedur LOTO harus dilakukan agar program LOTO dapat dijalankan dengan tepat. Setiap melakukan pekerjaan LOTO harus dilakukan inspeksi tentang prosedur LOTO agar menjamin LOTO dapat berjalan dengan tepat.

Penggunaan hidran dalam proses pemadaman kebakaran sangat bergantung pada sumber air yang digunakan. Sumber air yang digunakan harus dapat memberikan suplai air secara terus menerus selama 30 menit seperti yang diatur pada Kepmen PU NO.02/KPTS/1985 tentang ketentuan pencegahan dan penanggulangan kebakaran pada bangunan gedung pasal 20 ayat 3 huruf a. Tangki air yang dimiliki oleh PT Petrokimia Gresik sebagai sumber air sebesar $9500 \mathrm{~m}^{3}$ dan dapat digunakan lebih dari 30 menit, hal tersebut sudah sesuai untuk melakukan pemadaman kebakaran.

Pompa juga merupakan hal yang sangat penting dalam proses pemadaman kebakaran, tanpa adanya pompa yang memadai sumber air tidak akan dapat dialirkan ke sumber titik kebakaran. Pompa air berfungsi untuk mempertahankan tekanan yang ada pada hidran, tekanan tersebut harus dijaga agar air yang dikeluarkan dapat dengan efektif melakukan pemadaman.

Ada 3 jenis pompa yang dimiliki oleh PT. Petrokimia Gresik yaitu jockey pump, main pump, dan diesel pump. Jockey pump dan main pump bekerja secara otomatis dengan tenaga listrik dan diesel pump menyala otomatis dan mati secara manual bertenaga diesel. Sumber listrik yang digunakan untuk pompa hidran juga ada dua sumber yaitu listrik PLN dan listrik pengolahan pabrik seperti turbin dan batubara.

Water spray merupakan ujung dari hidran conveyor yang digunakan dalam proses pemadaman. Water spray seharusnya dapat bekerja secara otomatis dalam mendeteksi suara panas atau indikasi kebakaran namun hal tersebut tidak dapat dilakukan pada conveyor lama. Operator harus menghubungi pihak utilitas untuk menambah tekanan jika terjadi suatu kebakaran. Hal tersebut sangat disayangkan karena kebakaran membutuhkan waktu yang sangat cepat dalam proses penanganan, jika harus melakukan komunikasi terhadap pihak utilitas ditakutkan waktu yang digunakan untuk komunikasi membutuhkan waktu yang lama dan api pada titik kebakaran akan semakin membesar. Water spray seharusnya dapat berjalan secara otomatis dengan adanya pendeteksi panas, jika pendeteksi panas menyala maka maka alarm kebakaran menyala dan pressure switch pada hidran akan terbuka untuk melakukan pemadaman. Kegagalan instrumentasi ini masih dalam perbaikan oleh PT Petrokimia Gresik.

Instalasi kebakaran automatis harus dilakukan pengujian dan berfungsi baik serta disahkan oleh direktur, hal tersebut diatur pada PER. 02/ MEN/1983 tentang instalasi alarm kebakaran pasal 55. Panjangnya conveyor yang dimiliki dan potensi bahan yang diangkut seharusnya permasalahan tentang tidak berfungsinya alat otomatis harus segera diperbaiki untuk menghindari keadaan kecelakaan kebakaran yang tidak diinginkan, alat harus selalu siap untuk melakukan pemadaman dengan waktu secepat cepatnya agar dampak dari kebakaran tidak bertambah luas.

Semua aspek dalam penggunaan konstruksi pengaman dan desain pengaman conveyor harus diperhitungkan. Bahaya harus dicegah dengan adanya pengaman conveyor. Permasalahan hal ergonomis adalah hal yang penting untuk dipertimbangkan. Mengurangi potensi bahaya fisik dan meningkatkan keamanan adalah prinsip ergonomis. Pengaman conveyor harus dirancang agar berat dan dimensi dapat dengan mudah melakukan penanganan jika terjadi suatu kecelakaan.

PER.05/Men/1985 pasal 77 conveyor harus dilengkapi dengan tempat jalan kaki atau teras pada seluruh panjangnya dengan lebar tidak kurang dari 


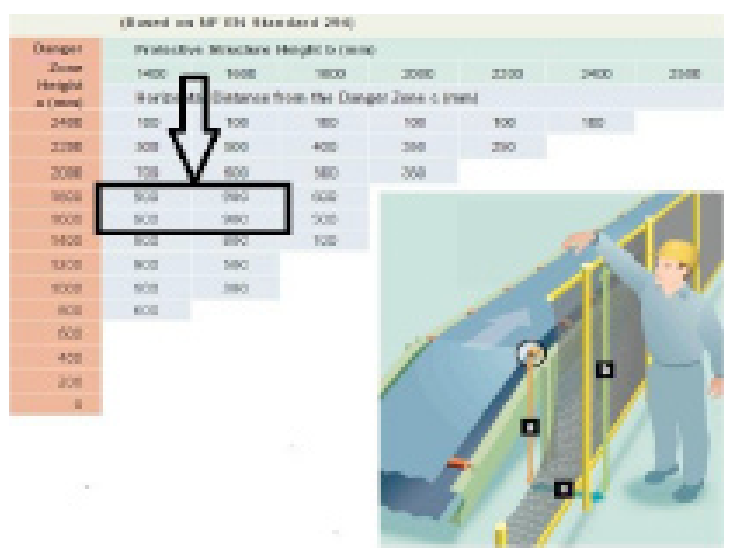

Gambar 2. Standar Ketinggian Pengaman Conveyor

$45 \mathrm{~cm}$ dan mempunyai sandaran standar dan atau pagar tepi. Berdasarkan PER. 05/Men/1985 pasal 78 tentang pita berjalan atau conveyor sabuk, rantai transmisi, poros penggerak, tabung-tabung atau cakra dan roda gigi pada peralatan dan penggerak harus diberi pengaman sesuai dengan peraturan yang berlaku untuk perlengkapan transmisi tenaga mekanis.

Hasil pengamatan dan pengukuran saat melakukan observasi lapangan menunjukkan bahwa pengaman conveyor terbuka pada conveyor belerang memiliki jarak dari conveyor ke pagar pembatas sepanjang 2 meter atau $2000 \mathrm{~mm}$ dan memiliki tinggi pagar sekitar $1,5 \mathrm{~m}$ atau $1500 \mathrm{~mm}$ dan ketinggian zona bahaya conveyor $1,7 \mathrm{~m}$ atau $1700 \mathrm{~mm}$. Hal tersebut sudah sesuai dengan $n f$ en standards 294, tentang standar conveyor. Jika di konversi kan ke dalam tabel, ketinggian conveyor $1700 \mathrm{~mm}$ dan tinggi pagar pembatas $1500 \mathrm{~mm}$ maka dapat disimpulkan bahwa jarak antara pagar dan conveyor agar menciptakan suasana paling aman maka paling sedikit yaitu $900 \mathrm{~mm}$. Hal tersebut sudah sesuai karena jarak horizontal antara conveyor dan pagar pembatas conveyor pelabuhan PT. Petrokimia Gresik ialah $2000 \mathrm{~mm}$.

Rambu tanda bahaya merupakan salah satu rambu-rambu keselamatan kerja, yang berfungsi untuk memperingatkan orang-orang terhadap suatu potensi bahaya yang dapat menyebabkan kerugian baik pada orang atau korban berupa cidera dan kematian maupun pada perusahaan berupa ganti rugi aset maupun hilangnya jam produksi. Berdasarkan OSHA standar tahun 2013, rambu-rambu keselamatan kerja terdiri dari warna khusus, kata informasi pada media dengan adanya simbol tanda keselamatan dan menggunakan kata tanda bahaya seperti DANGER, CAUTION, WARNING dengan arti sesuai dengan tingkat risiko bahaya.

Pada beberapa titik jalur yang dilalui oleh pekerja sangat rawan dan memiliki potensi bahaya yang cukup besar, seperti melewati bagian bawah conveyor yang berpotensi kejatuhan material, melewati dekat dengan roda-roda conveyor yang sedang berputar. Area tersebut sering dilalui oleh pekerja sehingga perlu adanya penambahan rambu-rambu sebagai pengingat potensi bahaya seperti awas benda berputar, awas kepala, awas tertimpa material, awas terjepit, dilarang berdiri di bawah conveyor, dilarang mengoperasikan selain petugas dilarang melintas selain petugas.

Panjangnya conveyor belerang dari pelabuhan hingga gudang yang dimiliki PT Petrokimia Gresik dan tidak dapat terlihat oleh operator dari ujung ke ujung maka perlu adanya rambu-rambu seperti alarm atau gong jika terjadi perubahan gerakan atau saat awal conveyor dijalankan dan saat conveyor dimatikan sesuai dengan peraturan menteri pasal 83, PER.05/Men/1985 tentang pesawat angkat angkut. Berdasarkan hasil observasi di lapangan saat melakukan pengambilan data, alarm tersebut tidak ada. Alarm tersebut sangatlah penting karena jika ada pekerja yang sedang melakukan pekerjaan di area conveyor dan terdengar alarm tersebut maka pekerja tersebut dapat segera menghindar dari area conveyor, dengan begitu risiko terjadinya kecelakaan akan dapat diperkecil.

Undang-Undang Nomor 13 Tahun 2003 tentang ketenagakerjaan bab V. Pelatihan kerja adalah keseluruhan kegiatan untuk memberi, memperoleh, meningkatkan, serta mengembangkan kompetensi kerja, produktivitas, disiplin, sikap, dan etos kerja pada tingkat keterampilan dan keahlian tertentu sesuai dengan jenjang dan kualifikasi jabatan atau pekerjaan.

Salah satu pengendalian administratif yang dapat dilakukan ialah dengan melaksanakan pelatihan kerja. Pemberian bekal pendidikan sebelum melakukan pekerjaan pada pekerja baru merupakan hal yang wajib dilakukan perusahaan. Pelatihan kerja dapat meliputi tentang jenis pekerjaan, pengoperasian alat, dan potensi-potensi bahaya pada alat tersebut. Pemberian wawasan potensi bahaya sejak dini merupakan hal yang sangat penting karena dapat memproteksi pekerja untuk melakukan suatu tindakan yang tidak aman yang dapat membahayakan pekerja dan perusahaan. PT 
Petrokimia Gresik sudah melakukan pelatihan kerja pada seluruh pekerja sehingga dapat dikategorikan baik.

Pekerjaan pada unit kerja masing-masing membutuhkan suatu prosedur yang disebut sebagai prosedur kerja. Prosedur kerja dapat berisi teng langkah-langkah pekerjaan yang berhubungan dengan bagian atau unit lain. sebagai contoh prosedur kerja yaitu prosedur pengoperasian conveyor belerang. Berdasarkan hasil wawancara pada saat pengumpulan data pekerja sudah mengetahui tentang prosedur-prosedur yang dimiliki pada perusahaan untuk pengoperasian belerang dan berdasarkan observasi prosedur-prosedur tersebut sudah terdokumentasi dengan baik.

Safety talk merupakan suatu kegiatan untuk mengarahkan pekerja dengan menggunakan suatu pedoman text khusus yang sudah disiapkan dan dibacakan oleh salah satu pekerja menggunakan pengeras suara pada saat akan melaksanakan pekerjaan. Penerapan safety talk sebagai pengendalian administratif sudah diterapkan dengan baik pada unit kerja. Safety talk sangatlah penting sebagai pengingat pekerja akan potensi bahaya yang ada di tempat kerja sehingga pekerja dapat lebih berhati hati dalam melakukan pekerjaan.

Pengendalian administratif lainnya yaitu dengan menerapkan safety meeting, safety meeting merupakan suatu kegiatan rapat yang dilakukan oleh panitia pembina keselamatan dan kesehatan kerja (P2K3) PT. Petrokimia Gresik yang dilakukan selama 1 bulan sekali. Ada 2 macam safety meeting yaitu safety meeting corporate yang dihadiri oleh direktur produksi, manajer, staf keselamatan kerja, dokter perusahaan, direktur anak perusahaan untuk membahas tentang permasalahan, pengendalian dan tindakan pengendalian keselamatan dan kesehatan kerja (K3) dengan tingkat permasalahan besar yang tidak dapat ditangani di unit kerja setempat dan safety meeting unit setempat yang dihadiri oleh general manager, pimpinan unit kerja, staf $\mathrm{K} 3$, kepala bagian, safety representatif untuk membicarakan permasalahan, pengendalian dan tindakan pengendalian keselamatan dan kesehatan kerja (K3) dengan tingkat permasalahan kecil. Berdasarkan hasil observasi saat di lapangan safety meeting sudah diikuti oleh selurah pegawai berwenang dalam melaksanakan safety meeting di PT Petrokimia Gresik. Hasil safety meeting sudah terdokumentasi dengan baik, nantinya akan dilaporkan ke Dinas Tenaga Kerja Gresik seperti yang diatur pada PER. 04/MEN/1987 pasal 12 tentang tata cara pelaporan $\mathrm{P} 2 \mathrm{~K} 3$.

\section{SIMPULAN}

Berdasarkan hasil penelitian didapatkan hasil penerapan emergency pull cord dan emergency stop dapat dikategorikan baik, namun masih ada beberapa yang rusak dan perlu perbaikan. Penerapan prosedur lockout dan tag out (LOTO) memang sudah ada namun pekerja masih kurang konsisten dalam melakukan penerapan LOTO oleh karena itu LOTO di perusahaan dapat dikategorikan cukup. Untuk alat pengaman kebakaran sudah dimiliki dan terpasang pada sepanjang conveyor belerang PT Petrokimia Gresik. Kondisi alat pengaman kebakaran conveyor belerang dapat dikategorikan baik. Untuk desain pengaman conveyor berdasarkan standar $n f$ en standards 294 sudah baik. Untuk kondisi rambu-rambu keselamatan sudah terpasang sebagian dan masih perlu dilakukan penambahan pemasangan rambu-rambu keselamatan yang sudah disediakan di gudang rambu. Upaya pengendalian administratif seperti pelatihan kerja, prosedur kerja, safety talk dan safety meeting sudah dilaksanakan dengan baik.

\section{DAFTAR PUSTAKA}

Hidayatullah, A., 2013. Analisis Penerapan Sistem Lockout/Tag out (LOTO) pada Bagian Operasi dan Pemeliharaan di PT. X Tanjung Emas Kota Semarang. Jurnal Kesehatan Masyarakat Universitas DIponegoro, [e-Jurnal] 2 (1).

Keputusan Menteri Pekerjaan Umum Republik Indonesia Nomor 02/KPTS/1985 Tentang Ketentuan Pencegahan dan Penanggulangan Kebakaran pada Bangunan Gedung. Jakarta: Kementerian Pekerjaan Umum

Martinetti, A., Leo A.M. Van Dongen., Raffaele, R., 2016. A Back-Analysis on Conveyor Belt Injury for a Better Design for Maintenance Operations. American Journal of Applied Sciences, [e-Journal] 14 (1): pp. 1-12

OSHA., 2013. General industry and Construction. United State: Departemen of Labor United State

Peraturan Menteri Tenaga Kerja No. 02/MEN/1983 Tentang Instalasi Kebakaran Automatik. Jakarta: 
Kementerian Tenaga Kerja

Peraturan Menteri Tenaga Kerja No. 05/MEN/1985

Tentang Pesawat Angkat dan Angkut. Jakarta:

Kementerian Tenaga Kerja

Peraturan Menteri Tenaga Kerja Republik Indonesia No. 04/MEN/1987 Tentang Panitia Pembina Keselamatan dan Kesehatan Kerja Serta Tata Cara Penunjukan Ahli Keselamatan Kerja. Jakarta:

\section{Kementerian Tenaga Kerja}

Undang-Undang Nomor 1 Tahun 1970 Tentang Keselamatan Kerja. Jakarta: Kementerian Tenaga Kerja

Undang-Undang Nomor 13 Tahun 2003 tentang Ketenagakerjaan. Jakarta: Kementerian Tenaga Kerja

Vezina, G., 2003. A User's Guide to Conveyor Belt Safety. Bibliothèque nationale du Québec: ISBN 2-550-42283-X 